\title{
Erratum to: Five Reasons Why Cytoreductive Surgery Plus Hyperthermic Intraperitoneal Chemotherapy Must be Regarded as the New Standard of Care for Diffuse Malignant Peritoneal Mesothelioma
}

\author{
Paul H. Sugarbaker, MD, FACS, FRCS
}

Program in Peritoneal Surface Malignancy, Washington Hospital Center, Washington, DC

\section{ERRATUM TO: ANN SURG ONCOL \\ DOI 10.1245/S10434-010-1042-Z}

The title of the published letter-to-the-Editor entitled, "Five Reasons Why Cytoreductive Surgery Plus Hyperthermic Intraperitoneal Chemotherapy Must be Regarded as the New Standard of Care for Diffuse Malignant Peritoneal Mesotheliomia" (DOI 10.1245/s10434-010-1042-z) did not include the final word "Mesothelioma."

This letter was published online March 31, 2010.

The online version of the original article can be found under doi:10.1245/s10434-010-1042-z.

(C) Society of Surgical Oncology 2010

Published Online: 21 April 2010

P. H. Sugarbaker, MD, FACS, FRCS

e-mail: paul.sugarbaker@medstar.net 